\title{
El camino hacia la efectividad del derecho ambiental
}

\author{
Mario Peña Chacón ${ }^{1 *}$ \\ Universidad de Costa Rica, San José, Costa Rica.
}

(Enviado: Marzo, 2016. Aceptado para publicación: Junio, 2016)

\begin{abstract}
Resumen:
El principal problema actual del derecho ambiental es su falta de efectividad, existiendo claras falencias tanto en el logro de sus objetivos y metas, como en su aplicación y cumplimiento sostenido y recurrente. Ante tal problemática, el presente trabajo pretende exponer las principales causas generadoras de inefectividad del derecho ambiental, analizar sus efectos y consecuencias, así como explorar posibles soluciones que le permitan salir del estado actual de teatralidad y alcanzar efectividad y eficiencia plena, y con ello satisfacer el fin superior de conservación y uso racional, sostenible, equitativo y solidario de los bienes y servicios ambientales.
\end{abstract}

Palabras Claves: Eficacia; Efectividad; Eficiencia; Codificación; Hermenéutica ambiental; Principios de progresividad; Principio de prohibición de retroceso.

\begin{abstract}
:
The current main problem of environmental law is their lack of effectiveness, clear deficiencies exist to achieve its goals and objectives, and also in its implementation and sustained and recurring compliance. Due to this problem, this academic paper aims to clarify the main root causes of ineffectiveness of environmental law, analyzing its effects and consequences, and also explore possible solutions to enable it to exit the current state of theatricality and reach full effectiveness and efficiency, and thereby satisfy the main goal of conservation and rational, sustainable, equitable use of environmental goods and services.
\end{abstract}

Keywords: Efficacy; Effectiveness; Efficiency; Environmental hermeneutics; Progressive principle; Non regression principle.

"La palabra clave de nuestro tiempo es la de la efectividad de los derechos. Si a través de su ejercicio no se materializan de nada valen"

Ricardo Luis Lorenzetti

\section{Introducción}

El principal problema actual del derecho ambiental es su falta de efectividad, existiendo claras falencias tanto en el logro de sus objetivos y metas, como en su aplicación y cumplimiento sostenido y recurrente. A pesar del crecimiento exponencial que la normativa ambiental ha experimentado en las últimas décadas, tanto en el ámbito interno de los países como a través del derecho internacional ambiental, el orden público ambiental no ha logrado solventar los problemas ambientales que aquejan a la humanidad,

\footnotetext{
${ }^{1}$ Autor para correspondencia. Email: mariopenachacon@gmail.com

* Este artículo fue redactado dentro del Proyecto de Investigación denominado "Las clínicas del Derecho Ambiental y Gestión de Riesgos Climáticos a través de una cultura jurídica de la sostenibilidad y no regresión" inscrito ante la Vicerrectoría de Investigación y el Instituto de Investigaciones Jurídicas de la Universidad de Costa Rica bajo el código 722-B3-193. Coordinador de la Maestría en Derecho Ambiental de la Universidad de Costa Rica. Miembro de la Comisión de Derecho Ambiental de la Unión Internacional para la Conservación de la Naturaleza (UICN).
} 
siendo que, contrario a lo esperado; la crisis ambiental se ha incrementado de manera gradual y progresiva.

A todas luces el derecho ambiental ha fallado en garantizar el mantenimiento y aseguramiento del equilibrio ecológico, la eficiencia económica y la equidad social entre las actuales y futuras generaciones. Ante tal problemática, el presente trabajo pretende exponer las principales causas generadoras de inefectividad del derecho ambiental, analizar sus efectos y consecuencias, así como explorar posibles soluciones que le permitan salir del estado actual de teatralidad y alcanzar efectividad y eficiencia plena, y con ello satisfacer el fin superior de conservación y uso racional, sostenible, equitativo y solidario de los bienes y servicios ambientales.

\section{Eficacia, efectividad y eficiencia del derecho}

Los términos eficacia, efectividad y eficiencia suelen utilizarse de manera indiferenciada e incluso como sinónimos, sin embargo; desde una perspectiva estrictamente jurídica, poseen connotaciones especiales que posibilitan su distinción, las cuales rxpondremos a continuación, a efectos de determinar el alcance y enfoque de esta investigación.

La eficacia de las normas está vinculada estrictamente a la posibilidad de producir efectos jurídicos y por tanto, de ser aplicadas de manera plena e inmediata. Tratándose de leyes, la eficacia se da a partir de su entrada en vigor. ${ }^{2}$ Los actos administrativos de alcance general despliegan efectos luego de su debida publicación, ${ }^{3}$ mientras que los actos administrativos de alcance concreto a partir de la comunicación formal al destinatario, excepto si le concede únicamente derechos, en cuyo caso su eficacia corre desde que son adoptados. $^{4}$

Por su parte, la efectividad normativa está vinculada al logro de la totalidad de objetivos y metas trazados por el ordenamiento jurídico, así como a su aplicación, observancia y cumplimiento de forma sostenida y recurrente. Mientras tanto, la eficiencia implica la capacidad para lograr los objetivos y metas impuestos por la normativa promulgada empleando los mejores medios disponibles y por tanto, al menor costo económico, social y ambiental posible.

De esta forma, una norma será eficaz una vez que es promulgada y puesta en vigencia, independientemente de su grado de aplicación, del cumplimiento pleno de sus objetivos y del uso de los mejores medios existentes. Por su parte, para poder catalogar una norma como efectiva, es necesario primero verificar su eficacia en los términos antes expuestos, así como su aplicación sostenida y recurrente y el cumplimiento pleno de sus objetivos. La norma será efectiva cuando logre cumplir a cabalidad el propósito por el cual fue creada. Por último, la eficiencia será alcanzada únicamente cuando además de eficaz y

\footnotetext{
${ }^{2}$ El artículo 7 del Código Civil de Costa Rica, ley número 63 del 28 de setiembre de 1887 dispone que las leyes entran en vigor diez días después de su completa y correcta publicación en el Diario Oficial, siempre que en ellas no se dispone otra cosa.

${ }^{3}$ Artículo 240 inciso 1) de la Ley General de Administración Pública de Costa Rica, ley número 6227 del 2 de mayo de 1978.

${ }^{4}$ Artículo 140 de la Ley General de Administración Pública de Costa Rica, ley número 6227 del 2 de mayo de 1978.
} 
efectiva, la norma logre cumplir sus objetivos y metas utilizando los mejores y más adecuados medios disponibles, y al menor costo e impacto social, ambiental y económico.

\section{Inefectividad del derecho ambiental}

El jurista argentino CAFFERATTA ${ }^{5}$ nos recuerda que el mayor problema contemporáneo del Derecho Ambiental es la falta de efectividad normativa. Se sabe que existen leyes, pero no se sabe cómo lograr que esas leyes se cumplan. Al respecto, OJEDA MESTRE ${ }^{6}$ expone que el derecho ambiental ha sido, especialmente en países en desarrollo, un Derecho que padece de raquitismo de eficiencia, aunque destaca que la tensión entre facticidad y validez no es exclusiva de esta rama emergente del derecho.

Lo anterior ocurre pese al mandato claro y contundente contenido en el principio 11 de la Declaración de Río sobre Medio Ambiente y Desarrollo: "Los Estados deberán promulgar leyes eficaces sobre el medio ambiente. Las normas, los objetivos de ordenación y las prioridades ambientales deberían reflejar el contexto ambiental y de desarrollo al que se aplican. Las normas aplicadas por algunos países pueden resultar inadecuadas y representar un costo social y económico injustificado para otros países, en particular los países en desarrollo."

Si bien la normativa ambiental se ha incrementado de forma exponencial a partir de la década de los setenta del siglo anterior, lo cierto del caso es que no ha logrado solventar la crisis ambiental, la cual se acrecienta de manera gradual y progresiva, situación que para BRAGA NAVARRO ${ }^{7}$ constituye una verdadera paradoja: cuantas más leyes ambientales, más se agrava la crisis ambiental. Lo anterior es secundado por OJEDA MESTRE $^{8}$ cuando expone que "Cada día hay más juicios y más jueces ambientales, más leyes, más agencias, programas, ministerios, pero también hay nuevas agresiones al medio ambiente; pero también es verdad que las instancias internacionales de la ONU y otras, carecen de recursos suficientes". En esa misma línea, coincidimos con GONZÁLEZ BALLAR ${ }^{9}$ en que marcos normativos modernos, amplios y llenos de requisitos y controles administrativos, no necesariamente garantizan una gestión ambiental efectiva.

Si seguimos el ejercicio de distinción que realiza BENJAMIN ${ }^{10}$ entre regulación o normativización jurídica ambiental -regulation-; implementación jurídica -enforcement; respeto, obediencia o cumplimiento legal ambiental -compliance-; y por último, disuasión o desestímulo al incumplimiento de la norma -deterrence-, es posible afirmar que el actual derecho ambiental apenas ha logrado superar la etapa regulatoria, teniendo

\footnotetext{
${ }^{5}$ Cafferatta, N. 2007, "De la efectividad del derecho ambiental." La Ley, ejemplar del 2 de octubre de 2007.

${ }^{6}$ Ojeda Mestre, R. 2003, "El Derecho Ambiental del Siglo XXI." Medio Ambiente \& Derecho, Revista Electrónica de Derecho Ambiental, Universidad de Sevilla, número 9.

${ }^{7}$ Braga Navarro, G. 2015, Hermenéutica filosófica e direito ambiental: concretizando a justicia ambiental, Instituto O Direito por um Planeta Verde, São Paulo.

${ }^{8}$ Ojeda Mestre, R. 2003, "Las cien caras del derecho ambiental." Medio Ambiente \& Derecho, Revista Electrónica de Derecho Ambiental, Universidad de Sevilla, número 9.

${ }^{9}$ González Ballar, R. 2007, Verdades incómodas sobre la gobernabilidad ambiental en Costa Rica, Editorial Jurídica Continental, San José.

${ }^{10}$ Benjamin, A. 2003. En obra colectiva "Direito Água e Vida", Volumen 1, pág. 355, O Estado teatral e a implementação do Direito Ambiental, de los trabajos presentados en el $7^{\circ}$ Congresso Internacional de Direito Ambiental, San Pablo 2 al 6 de junio, Impresa Oficial.
} 
pendiente alcanzar las subsiguientes fases de implementación, obediencia y disuasión, para con ello lograr su efectividad y eficiencia. El derecho ambiental requiere de su implementación efectiva para dejar de ser, según BENJAMIN,${ }^{11}$ el verdadero patito feo del fenómeno jurídico, y con ello evitar caer en el censurable Estado Teatral - ley simbólica, que para este connotado jurista brasileño es aquél que, al regular la protección del medio ambiente, mantiene una situación vacua entre la ley y la implementación.

Por su parte, PRIEUR ${ }^{12}$ afirma que a pesar de tratarse de un derecho finalista, el derecho ambiental se topa actualmente con actitudes de resistencia y oposición por razones económicas o políticas. Asimismo, es frecuente el incumplimiento de sus objetivos debido a una vulneración directa del derecho existente o de una pasividad de las autoridades administrativas que no ejercen correctamente su obligación de control. La ausencia de efectividad del derecho aplicable constituye para el jurista francés, por sí misma una regresión.

Ante la problemática de la implementación efectiva del derecho ambiental JORDANO FRAGA llega a la conclusión de que: "el derecho que no es coercible no es derecho", frase que podríamos complementar afirmando que: "el derecho que no es efectivo tampoco merece llamarse derecho". Es claro que el derecho ambiental ha fallado en garantizar el mantenimiento y aseguramiento del equilibrio ecológico, la eficiencia económica y la equidad social entre las actuales y futuras generaciones. Por ello, y como bien lo afirma el maestro BENJAMIN:13 "hoy más que nunca, la implementación se transforma en un elemento esencial e imprescindible de la tutela jurídica del medio ambiente".

\section{Causas y consecuencias de la inefectividad del derecho ambiental}

Al estado actual del derecho ambiental a nivel global, resulta imposible aún hablar de efectividad y mucho menos de eficiencia, de ahí la relevancia de determinar las principales causas generadoras y sus efectos con la finalidad de conocer la magnitud del problema y plantear posibles soluciones.

\subsection{Cantidad y multiplicación de normativa ambiental}

Tal y como se expuso anteriormente, en las últimas décadas el derecho ambiental ha experimentado un crecimiento significativo tanto nivel del derecho interno de los Estados como a través del derecho internacional por medio de declaraciones de soft law ${ }^{14}$ así como de tratados bilaterales, regionales y globales vinculantes. A pesar de lo anterior, los problemas ambientales se han incrementado en cantidad y gravedad, lo que demuestra

\footnotetext{
11 Ibíd.

${ }^{12}$ Prieur, M. 2012 El nuevo principio de no regresión en derecho ambiental, Bruxelles: Editions Bruylant. 13 Ibíd.

14 "Forman parte del soft law o derecho blando todas aquellas resoluciones y declaraciones de principios emanadas de Conferencias y Organismos Internacionales. Se trata de principios que se proponen en abstracto para orientar la conducta de los Estados. La doctrina los ha calificado como normas programáticas, las cuales disponen como los Estados deberían actuar, careciendo de obligatoriedad, limitándose a trazar un plan de acción futuro para el posterior desarrollo normativo del sector ambiente. El soft law no necesita del trámite normal que siguen los tratados internacionales para ser incorporados a los distintos ordenamientos jurídicos y su función se circunscribe a interpretar, integrar y delimitar el ordenamiento interno de los Estados". Peña Chacón, M. 2014, "Hacia una nueva hermenéutica ambiental", Revista Justicia Ambiental, número 6, Chile.
} 
que el derecho ambiental y la multiplicación de sus normas no han logrado resolver los problemas ambientales.

Ello encuentra justificación si tomamos en cuenta los siguientes factores que coadyuvan a la inefectividad del derecho ambiental:

- Modificación constante y acelerada de normas ambientales no acompañadas de procesos derogatorios claros ni completos.

- Copia de normas y estándares de otros países que no responden a la realidad ambiental, social ni económica del país que los adopta.

- Aprobación de normas sin planes de aplicación y cumplimiento que garanticen la existencia de capacidad técnica, institucional y presupuestaria para su efectiva implementación.

- Ratificación de tratados internacionales ambientales sin adaptación de la normativa interna a los nuevos requerimientos y obligaciones contraídas a través de su suscripción.

- Distanciamiento entre las normas promulgadas y las políticas ambientales adoptadas a nivel global, regional y local.

- Constantes antinomias entre legislación que regula el libre comercio y la inversión en relación a la normativa ambiental.

Lo anterior ha tenido como consecuencia la proliferación y multiplicación de legislación ambiental que califica como dispersa, fragmentada y contradictoria, ante la ausencia de un verdadero, coherente y sistémico orden público ambiental, ${ }^{15}$ lo cual favorece el desconocimiento e ignorancia del derecho, su inobservancia, confusión y errónea aplicación del derecho de fondo, generando con ello inseguridad jurídica entre aplicadores y destinatarios de las normas.

\subsection{Promulgación de políticas, normas y jurisprudencia regresivas}

A través de procesos de desregulación y simplificación de trámites, con la finalidad de favorecer el clima de negocios y la competitividad, en los últimos años se han venido promulgando políticas y normativas que califican como regresivas a la luz del principio de no regresión ambiental o de prohibición de retroceso.

En trabajos académicos anteriores ${ }^{16}$ hemos expuesto que una norma califica como regresiva cuando su grado de efectividad resulte ser inferior en comparación al alcanzado con anterioridad, en la medida que derogue, limite, restrinja, reduzca, relaje o flexibilice el nivel de protección ambiental previamente adquirido, siempre y cuando no cuente con

\footnotetext{
15 "En su conjunto, las fuentes formales y materiales, conforman el orden público ambiental constituido por normas escritas tales como: Constitución Política, convenios, tratados y declaraciones internacionales (soft law y hard law), leyes, decretos, reglamentos, estatutos, circulares, directrices; y por no escritas: costumbre, usos, jurisprudencia y principios generales del derecho. Por medio del orden público ambiental el Estado busca la satisfacción de los intereses del conjunto social (interés público ambiental) que además representan un orden inter e intrageneracional, mismo que se vio consolidado a partir de la reforma operada en 1994 al artículo 50 constitucional, al reconocer un modelo de desarrollo económico y social respetuoso y coherente con un ambiente sano y ecológicamente equilibrado como primer paso para la consolidación de un Estado Social y Ambiental de Derecho". Peña Chacón, M. 2014, "Aplicación de la regla de la norma más favorable en el derecho ambiental." Revista Iberoamericana de Derecho Ambiental y Recursos Naturales, número 11, Argentina.

${ }^{16}$ Peña Chacón, M, 2013, “Test de Regresividad Ambiental”, Revista Internacional Direito Ambiental (RIDA), número 6, Brasil.
} 
justificación ni respaldo técnico-científico que permita determinar, en grado de certeza, la no afectación del bien jurídico objeto de tutela. De esta forma, la nueva norma no debe ni puede empeorar la situación del derecho ambiental preexistente, desde el punto de vista de su alcance, amplitud y especialmente, de su efectividad.

También califica como regresión la omisión, por parte de los poderes estatales, de ejercer su potestad normativa, especialmente la reglamentación de leyes ambientales, o bien, cuando esta potestad se ejerce de manera parcial, incompleta o errónea desde un punto de vista científico, técnico y jurídico, tornando al derecho inaplicable. A la vez, la inefectividad a raíz del incumplimiento e inobservancia sistemática en la aplicación de la legislación ambiental constituye una violación al principio de prohibición de retroceso.

Las políticas de mejora regulatoria y simplificación de trámites administrativos tienen como norte el establecimiento de nuevas regulaciones claras y sencillas; eliminar duplicidades, contradicciones y discrecionalidad; prescindir de requisitos innecesarios; establecer plazos de resolución definidos, en fin, disminuir, mejorar y simplificar los trámites ante entidades gubernamentales. La mejora regulatoria busca que el ciudadano cuente con reglas claras y reciba de la administración pública servicios más ágiles, que el empresario asigne sus recursos a producir y no a la tramitología, y que, por ende, el Estado aumente su productividad, utilice de forma más eficiente sus recursos y minimice la corrupción.

A pesar de las bondades antes expuestas, las ideas desreguladoras, mal entendidas y aplicadas, traen consigo efectos negativos en la política ambiental, en especial la reducción de presupuestos, desmantelamiento de programas de intervención del Estado, así como la rebaja, disminución o relajación e incluso la derogación de normativa que protege al medio ambiente. ${ }^{17}$ Por medio de procesos de desregulación y simplificación de trámites, y en muchos casos por razones eminentemente políticas y económicas, tales como cambios de gobierno o bien crisis económicas, grupos de presión logran romper el equilibrio óptimo entre los aspectos ambientales, sociales y económicos propios del desarrollo sostenible, en favor del crecimiento económico a través de la derogación o modificación de normativa ambiental. ${ }^{18}$ De esta forma, escudándose en la simplificación del derecho, los Estados han aprovechado para disminuir de forma insidiosa el nivel de protección, procediendo en realidad a un retroceso del derecho existente y de la tutela efectiva del medio ambiente. ${ }^{19}$

\subsection{Promulgación de normas sin participación pública en su elaboración}

\footnotetext{
17 "El impacto de la desregulación no sólo debe medirse en términos de batalla ideológica mercadointervención. La desregulación-liberalización impacta sobre la propia estructura técnica del Derecho Ambiental o los principios constitucionales; Koepfer ha destacado tres serias objeciones frente a los nuevos instrumentos desde el punto de vista del Estado de Derecho: seguridad jurídica, reserva de Ley y principio de igualdad; problemas de tutela jurídica para los terceros y pérdidas de la posibilidad de impugnar y, por último, problemas derivados de la acumulación desordenada de instrumentos" "En torno a las nuevas formas de actuación medioambientales del Estado", D.A., 1993, citado por Jordano Fraga, 2002, J. "Derecho Ambiental Siglo XXI, Medio y Derecho", Revista Electrónica de Derecho Ambiental, número 9, Universidad de Sevilla.

${ }^{18}$ Peña Chacón, M. 2013, “Desregulación versus Legislación Ambiental”, artículo de opinión publicado en el diario La Nación del 15 de junio de 2013, accesible a través del siguiente enlace:

19 Prieur, M. 1987, "La déréglementation en matière d'environnement", Revue juridique de l'environnement, número 3.
} 
Para OJEDA MESTRE ${ }^{20}$ no hay más de dos clases de derecho ambiental: "El derecho ambiental democrático y participativo y el antidemocrático y excluyente, siendo imposible concebir o entender esta rama jurídica sin invocar a la presión y participación social". La ausencia de participación pública durante la elaboración de normas ambientales, incluso desde sus etapas previas, trae como consecuencia su desconocimiento generalizado, especialmente por parte de los destinatarios de la normativa, así como falta de apropiación e internalización, desconfianza, e ineludiblemente su inobservancia e incumplimiento.

\subsection{Promulgación de normas sin considerar grupos vulnerables, enfoque de equidad social, identidad cultural de los pueblos autóctonos, ni el cambio climático.}

Al igual que como se expuso en el punto anterior, normas ambientales que no integren desde su concepción la participación efectiva de grupos vulnerables tales como niños, jóvenes, personas con discapacidad, en situaciones de vulnerabilidad, pobreza, analfabetismo, pueblos indígenas y tribales, mujeres y ancianos; que no contemplen factores como la equidad social, la pluriculturalidad y pluridiversidad; y que no tomen en consideración el enfoque integral de mitigación y adaptación al cambio climático, están condenadas al fracaso, en virtud a la falta de apropiación e internalización por parte de sus destinatarios, lo que conlleva a su inobservancia e incumplimiento generalizado.

\subsection{Ausencia o poco desarrollo de normativa procesal ambiental, procedimientos especiales ambientales ni jurisdicciones ambientales especializadas.}

La inexistencia o poco desarrollo doctrinario, normativo y jurisprudencial de un derecho procesal ambiental integral que contemple procedimientos administrativos $\mathrm{y}$ jurisdiccionales específicos para la problemática ambiental, ha traído como consecuencia que este tipo de conflictos sean de conocimiento de jurisdicciones y procesos no adaptados a la realidad ambiental, en la mayoría de los casos procesos lentos, inadecuados, pasivos, formales, rígidos y legalistas, generando incerteza e inseguridad entre los distintos sujetos procesales, así como problemas en la aplicación efectiva de las normas sustantivas, lo cual hace imposible alcanzar el fin de una justicia ambiental pronta y cumplida.

A lo anterior debe sumársele el hecho de que los procesos ambientales en muchos casos son conocidos por jueces no especialistas en la materia, así como por operadores jurídicos tales como fiscales, procuradores, defensores públicos y abogados litigantes sin conocimientos ni capacitación especializada en la materia, todo lo cual trae como consecuencia la errónea aplicación del derecho de fondo, impunidad e injusticia ambiental.

\subsection{Escaso desarrollo de mecanismos de solución alternativa de conflictos ambientales}

Los mecanismos de solución alternativa de conflictos ambientales, entre ellos la conciliación, transacción y el arbitraje; se constituyen en instrumentos de paz social y de satisfacción del interés público ambiental. Su ausencia o insuficiente implementación, tanto a nivel judicial como extrajudicial, provoca ineludiblemente la judicialización de

\footnotetext{
${ }^{20}$ Ojeda Mestre, R, Op.cit.
} 
los conflictos ambientales y con ello el aumento en la litigiosidad e injusticia ambiental, lo anterior tomando en cuenta los aspectos desarrollados en el acápite anterior en cuanto al escaso o poco desarrollo de normas procesales, procedimientos y jurisdicciones especializadas en materia ambiental, que permitan el cumplimiento sostenido y recurrente, y la aplicación efectiva de la normativa ambiental sustantiva.

\subsection{Sistemas de responsabilidad por daño ambiental inexistentes o incompletos}

Partiendo del hecho de que la responsabilidad por daño ambiental es a la vez preventiva, precautoria, reparatoria, compensatoria e indemnizatoria, y que los sistemas de responsabilidad deben estar basados en criterios de responsabilidad objetiva, solidaria, inversión de la carga de la prueba, obligación de recomposición del ambiente, todo bajo un enfoque de una responsabilidad integral, su ausencia o incompleta implementación a través de normas específicas y diferenciadas trae como consecuencia impunidad, socialización de los daños ambientales e injusticia ambiental.

Lo anterior se ve agravado por el hecho de que en muchos sistemas normativos aún no es posible que una misma conducta o un mismo hecho pueda generar responsabilidad civil, penal y administrativa de forma concomitante y no excluyente; por la existencia de sanciones débiles y por la ausencia de reglas claras y específicas sobre recomposición, indemnización y valoración económica del daño ambiental. No en pocas ocasiones las sentencias condenatorias por daño ambiental, independientemente de la vía procesal en que sean dictadas, son omisas en fijar claramente las responsabilidades del caso ni ordenan la inmediata recomposición del ambiente degradado, tampoco definen los parámetros a seguir para su efectiva reparación, ni cuantifican ni fijan la indemnización por el daño ambiental, no indican expresamente la finalidad ambiental que debe atenderse, ni el órgano o entidad pública responsable de darle el destino señalado. El control y fiscalización de las sentencias condenatorias por daño ambiental es escaso o nulo, así como los mecanismos procesales para su ejecución.

Especial mención merecen las medidas alternativas a la pena de prisión en boga en los Códigos Procesales Penales de la región latinoamericana, tales como la conciliación, criterio de oportunidad, suspensión del proceso a prueba, beneficio de ejecución condicional de la pena, reparación integral del daño, entre otras. Tales medidas, en virtud de su errónea interpretación y aplicación, se han llegado a convertir en incentivos perversos para la destrucción de los bienes ambientales, debido a que los condenados beneficiados con las medidas alternativas en delitos ambientales, no se ven obligados a cumplir la pena de prisión impuesta, ni tampoco a reparar integralmente el daño social y ambiental ocasionado con sus conductas, siendo un fiel reflejo de la inefectividad del derecho penal para resolver los problemas ambientales.

\subsection{Ausencia de criterios específicos de interpretación y aplicación de la normativa ambiental}

Ante la ausencia de criterios especiales de interpretación de las normas ambientales se ha echado mano de las reglas hermenéuticas tradicionales propias de otras ramas del derecho como el civil y comercial, que poseen un enfoque eminentemente antropocéntrico, individualista y economicista, y que a todas luces, no se adaptan a la materia ambiental contribuyendo a su inefectividad. 
La aplicación de criterios interpretativos no aptos para el derecho ambiental ha traído como consecuencia la inobservancia sistemática de los principios generales del derecho ambiental y su rol interpretador, integrador y delimitador del orden público ambiental, y con ello la errónea aplicación del derecho sustantivo y procesal, la desaplicación singular de normas ambientales por razones políticas, económicas y sociales, generando confusión e incoherencia en su aplicación, desconfianza entre sus aplicadores y destinatarios e inseguridad jurídica.

\subsection{Débil implementación de los Derechos de Acceso}

El Principio 10 de la Declaración de Río sobre Medio Ambiente y Desarrollo dispone que el mejor modo de tratar las cuestiones ambientales es con la participación de todos los ciudadanos interesados, en el nivel que corresponda. En el plano nacional, toda persona deberá tener acceso adecuado a la información sobre el medio ambiente de que dispongan las autoridades públicas, incluida la información sobre los materiales y las actividades que encierran peligro en sus comunidades, así como la oportunidad de participar en los procesos de adopción de decisiones. Los Estados deberán facilitar y fomentar la sensibilización y la participación de la población poniendo la información a disposición de todos. Deberá proporcionarse acceso efectivo a los procedimientos judiciales y administrativos, entre éstos el resarcimiento de daños y los recursos pertinentes.

Del principio 10 de Río derivan los denominados derechos de: acceso a la información ambiental, participación efectiva en la toma de decisiones ambientales y a mecanismos efectivos de justicia ambiental. La ausencia, o bien la débil implementación de los derechos de acceso, trae como resultado desconocimiento generalizado del marco jurídico, especialmente por parte de los destinatarios de la normativa, así como falta de apropiación e internalización, desconfianza, inobservancia, incumplimiento e injusticia ambiental.

\subsection{Débil institucionalidad ambiental}

La institucionalidad ambiental se ha caracterizado por los serios problemas de vacíos y traslapes de competencias; por el bajo nivel de coordinación inter e intra institucional; falta de capacidad administrativa; bajos presupuestos y ausencia de inversión; fiscalización escasa, nula, irregular, anormal, incluyendo aquella dirigida a actividades peligrosas; por su gestión basada casi exclusivamente en mecanismos de comando y control, y por la ausencia o insuficiencia de instrumentos económicos y voluntarios de gestión ambiental. Una débil institucionalidad es incapaz de resolver la creciente problemática ambiental generando incoherencias en la aplicación del marco jurídico, pérdida de confianza por parte de los administrados e inseguridad jurídica.

\section{Posible soluciones}

Alcanzar la efectividad y eficiencia del derecho ambiental requerirá a mediano y largo plazo de la implementación de un marco jurídico ambiental coherente, articulado y sistémico como un paso fundamental para consolidar el Estado Ambiental de Derecho. ${ }^{21}$

21 "Forma de Estado que se propone aplicar los principios de solidaridad económica y social para alcanzar el desarrollo sustentable, orientado a buscar la igualdad sustancial entre los ciudadanos, mediante el control jurídico del uso racional del patrimonio natural". Capella, V. 1994, Ecología: de las razones a los derechos. Granada, Ecorama. 
Ello sería posible a través de procesos normativos cuya finalidad sea lograr la coordinación, sistematización, limpieza de aporías, antinomias y la racionalización del orden público ambiental. En palabras del profesor JORDANO FRAGA:22 "Si el siglo XIX fue el de la codificación civil iniciada por el Código de Napoleón, el siglo XXI va a ser el siglo de la Codificación Ambiental".

La promulgación de nuevas normas ambientales y los procesos de codificación, deben incluir la modificación y adaptación de la normativa interna respecto al derecho internacional ambiental, así como la armonización del marco jurídico regulatorio respecto a las políticas ambientales vigentes. La voluntad política del Estado y el apoyo de la sociedad civil son claves para lograr su efectividad y eficiencia.

El respaldo serio y decidido de ONU y su Programa Naciones Unidas para el Medio Ambiente a los procesos de elaboración y negociación de instrumentos internacionales ambientales se constituye en un pilar fundamental que podría llegar a corregir las distorsiones generadas por los procesos de libre comercio sobre el medio ambiente.

A corto plazo, la hermenéutica ambiental se debe posicionar como una herramienta fundamental, esencial e imprescindible para alcanzar la coherencia del orden público ambiental, así como en el punto de apoyo que permitiría arrancar al derecho ambiental de su estado de parálisis de efectividad. ${ }^{23}$

El carácter finalista y evolutivo del derecho ambiental, su condición de derecho humano fundamental y la consolidación de sus principios generales obligan un nuevo tratamiento interpretativo para el derecho ambiental sustantivo y procesal. A raíz de lo anterior, el enfoque hermenéutico debe dar el paso del antropocentrismo, individualismo y economicismo, hacia una nueva ética ambiental más cercana al ecocentrismo, de solidaridad intergeneracional y cooperación. ${ }^{24}$

Debe dársele prioridad a la función de interpretación, integración y delimitación de los principios generales del derecho ambiental: preventivo, precautorio, progresividad, no regresión, contaminador pagador y reparación integral; así como reconocer y aplicar los criterios propios de interpretación del derecho ambiental, entre ellos: indubio pro natura, interés público ambiental y la regla de aplicación de la norma más favorable para el ambiente.

Aplicando los criterios propios de interpretación del derecho ambiental el operador jurídico podrá flexibilizar las normas que en su aplicación, no sirvan para dar respuesta rápida, real, y efectiva a las diversas situaciones que se presentan frente a los desafíos ambientales de nuestro tiempo, teniendo como límite el respeto a la regla constitucional del debido proceso y derecho de defensa. Por ello, el aplicador del derecho se encuentra

22 Jordano Fraga, J. 2013, "El futuro del derecho ambiental. Medio Ambiente \& Derecho", Revista Electrónica de Derecho Ambiental, Universidad de Sevilla, número 24.

${ }^{23}$ Peña Chacón, M. 2014, "Hacia una nueva hermenéutica ambiental", Revista Justicia Ambiental, número 6, Chile.

${ }^{24}$ Braga, G, Op.cit.// Le apostamos a una postura ecléctica entre un antropocentrismo clásico de matriz filosófica cartesiana y un ecocentrismo puro, a través de la tesis denominada antropocentrismo alargado, antropocentrismo extendido o antropocentrismo jurídico ecológico, ampliamente desarrollada por la doctrina brasileña, entre otros por los connotados juristas MORATO LEITE y AYALA DE ARAUJO, quienes reconocen el valor intrínseco inherente tanto del ser humano como de otras formas de vida no humanas, incluyendo a la naturaleza. 
ante el reto de escoger y adoptar la vía más adecuada para cumplir con las obligaciones y fines que impone el orden público ambiental.

La promulgación de nuevas normas y estándares ambientales debe ajustarse a las reglas unívocas de la ciencia y la técnica, así como hacerse acompañar de planes de aplicación y cumplimiento que aseguren la existencia de capacidad técnica, institucional y presupuesto suficiente para su efectiva aplicación. De igual forma, los procesos normativos deben contemplar la creación de instancias de coordinación inter e intra institucionales de la gestión ambiental que a la vez incorporen la participación pública como medio para garantizar su aplicación efectiva.

Debe tenerse claro que normas creadas y aplicadas por algunos países pueden resultar inadecuadas y representar un costo social y económico injustificado para otros, en particular aquellos en vías de desarrollo.

Ante procesos de desregulación y simplificación de trámites con efectos en la reducción de presupuestos, desmantelamiento de programas de intervención del Estado, así como la rebaja, disminución o relajación e incluso la derogación de normativa que protege al medio ambiente, la solución debe ser el reconocimiento expreso de los principios de progresividad y prohibición de regresividad como principios generales del derecho ambiental, tanto a nivel normativo como jurisprudencial, así como la creación e implementación de mecanismos efectivos de acceso a la justicia que permitan impugnar de inconstitucionalidad, inconvencionalidad o ilegalidad la normativa que califique como regresiva. La eliminación de excesos en los trámites administrativos no podría generar bajo ningún supuesto la desprotección del ambiente, por tratarse de un interés jurídico superior. Siguiendo a PRIEUR: ${ }^{25}$ "el derecho ambiental será efectivo solamente cuando las modificaciones que le afecten impliquen un medio ambiente mejor y no peor que antes".

Siendo que los procesos normativos que incorporan desde su inicio una amplia participación pública y que además involucran a las autoridades locales y/o nacionales, repercuten positivamente en la calidad de la normativa impulsada así como en su fiscalización y cumplimiento, se hace imperativo la implementación de mecanismos de participación en la elaboración de normas ambientales tales como iniciativa popular, consulta pública, referéndum, entre otros.

De igual forma, los procesos de creación, implementación y aplicación de normas ambientales deben incluir la participación y garantizar la igualdad; no discriminación e inclusión de grupos vulnerables, entre ellos niños, jóvenes, personas con discapacidad, en situaciones de vulnerabilidad, pobreza, analfabetismo, pueblos indígenas y tribales, mujeres, ancianos; reconocer la pluriculturalidad y pluridiversidad e integrar el enfoque de cambio climático.

El derecho ambiental sustantivo necesita verse reforzado por normativa procesal que permitan su correcta, estricta y efectiva aplicación dentro de los procesos donde se discuten controversias de carácter ambiental. El derecho procesal ambiental, como parte integrante el derecho procesal social, busca otorgar el máximo de garantías procesales a

25 Prieur, M. 1987, "La déréglementation en matière d'environnement", Revue juridique de l'environnement, número 3. 
individuos y grupos especialmente vulnerables, para la defensa de sus derechos subjetivos, intereses legítimos y en especial, de los derechos de incidencia colectiva o supraindividuales.

Por lo anterior, los procesos donde se discuten controversias ambientales deben ser céleres, expeditos, informales, de tramitación preferente y tutela expedita; deben regirse por las reglas de la oralidad: inmediatez, concentración, publicidad, itinerancia, gratuidad. Las decisiones judiciales y administrativas deben estar basadas en criterios de justicia, equidad y búsqueda de la verdad real. El juez ambiental debe ser especialista en la materia, proactivo y con amplios poderes. Los procesos ambientales deben asegurar la prevención de los daños, cesación de perjuicios, recomposición ambiental y la indemnización de derechos subjetivos. En materia de acceso a la justicia, lo ideal es que el esquema de legitimación procesal sea expandido a tal punto, que cualquier sujeto, en defensa del interés público ambiental, pueda plantear las acciones necesarias para alcanzar tal fin.

Deben contemplarse mecanismos de resolución alternativa de conflictos ambientales incluyendo la posibilidad de la Administración Pública de alcanzar acuerdos. Las medidas cautelares deben ser amplias y posibles de implementar antes y durante la tramitación del proceso e incluso durante la etapa de ejecución de sentencia. La prueba debe ser analizada a la luz de la sana crítica racional y del criterio de interpretación indubio pro natura. Las audiencias deben ser en el sitio de afectación ambiental. Las sentencias deben ordenar la recomposición del ambiente e indemnización de derechos subjetivos y contemplar mecanismos efectivos de control y fiscalización. La implementación de seguros y fondos ambientales coadyuvarían a la recomposición de los ecosistemas degradados. En virtud al deber de transparencia y rendición de cuentas deben existir registros de procesos ambientales de acceso público donde se inscriban los asuntos tramitados, el estado del proceso, los fallos emitidos y su cumplimiento, las condenas que recaigan sobre los demandados y el cumplimiento de las mismas. ${ }^{26}$

Los sistemas de responsabilidad por daño ambiental deben ser a la vez preventivos, precautorios, reparatorios, compensatorios e indemnizatorios, y estar basados en las reglas de la responsabilidad objetiva, solidaria, inversión de la carga de la prueba, obligación de recomposición del ambiente, y la imprescriptibilidad del daño ambiental de carácter colectivo, todo bajo un enfoque de responsabilidad integral tanto de los daños patrimoniales como extrapatrimoniales. Se hace necesario empezar a cuestionarse la aplicación de sanciones pecuniarias con fines disuasivos y ejemplares, para daños ambientales graves y groseros, como complemento adecuado y accesorio a los principios contaminador - pagador y de reparación integral del ambiente. ${ }^{27}$

\footnotetext{
${ }^{26}$ Sobre derecho procesal ambiental se recomienda al lector el artículo del autor denominado "Hacia un proceso ambiental eficaz, Propuesta de norma modelo para Costa Rica", publicado en la Revista de Derecho Ambiental, número 42, mayo-junio 2015.

${ }^{27}$ Peña Chacón, M. 2012, "Daño social, daño moral colectivo y daños punitivos. Delimitaciones y alcances en materia ambiental”. Revista Direito Ambiental RDA, año 17, número 68, octubre-diciembre, Brasil.
} 
Tratándose de responsabilidad administrativa y penal es fundamental la expansión del delito ambiental y las sanciones administrativas con una función real y no meramente simbólica, así como extender la responsabilidad penal a la persona jurídica. Sin embargo, el arma ideal con la que cuenta el derecho ambiental para alcanzar su efectividad sigue siendo la prevención de las infracciones, lo cual se podría lograr mejorando la información y la participación ciudadana. El rol del derecho penal en la protección del ambiente debe fortalecerse a través de la imposición de la obligación de recomposición ambiental, tanto a los sujetos condenados por delitos ambientales como a aquellos a quienes se les otorga una medida alternativa a la pena de prisión. Debe tenerse presente que la restauración ambiental, en la medida de lo posible al estado anterior al daño, es una obligación de carácter constitucional, independientemente de la vía procesal o jurisdicción competente.

Es primordial garantizar el acceso fácil, rápido, efectivo, y práctico a la información ambiental; la participación ambiental a efectos de promover la inclusión social, la solidaridad, la erradicación de la pobreza y desigualdades, restablecer la salud y el equilibrio ambiental y eliminar las barreras de acceso a la justicia ambiental; mejorar los sistemas de denuncia y de inspecciones, así como establecer criterios marco para la actuación de fiscales y otros operadores jurídicos en infracciones administrativas y penales; garantizar la igualdad en las condiciones de accesibilidad y efectividad durante todas las etapas del proceso judicial y/o administrativo; así como promover la sensibilización y educación ambiental. La implementación efectiva de los derechos de acceso se constituye en un requisito sine qua non para alcanzar la efectividad del derecho ambiental. Un gran paso a nivel regional podría darse mediante la adopción de la Declaración sobre la Aplicación del Principio 10 de Río, auspiciada por la Comisión Económica para América Latina (CEPAL).

Ante una débil institucionalidad ambiental, la propuesta es su fortalecimiento mediante el reforzamiento de los medios de inspección y policía, la creación de mecanismos de coordinación inter e intra institucional, la modificación del marco normativo con el fin de aclarar las competencias ambientales, y el aumento racional y proporcionado de los presupuestos institucionales de acuerdo a las competencias otorgadas. La gestión ambiental podría mejorar si se le otorga énfasis a la prevención, participación y educación ambiental; la promoción de esquemas sostenibles a través de incentivos fiscales y no fiscales a sistemas de producción y consumo amigables con el ambiente, así como el establecimiento e implementación de mecanismos que estimulen positivamente a los sujetos obligados a su cumplimiento. El desarrollo de instrumentos económicos de regulación permite desincentivar conductas de producción y consumo no sostenibles, pudiendo constituirse en una fuente alternativa de recursos para el tema ambiental. No deben descuidarse los mecanismos de comando y control, pero deben complementarse con los instrumentos de mercado y los voluntarios. Por último, se hace imperativo el desarrollo de la contabilidad ambiental, así como la implementación de indicadores que permitan medir el nivel de efectividad de las normas ambientales.

Ciertamente el camino hacia la efectividad del derecho es largo, empedrado y sinuoso, OJEDA MESTRE nos recuerda que el "derecho ambiental nada contra corriente y en aguas contaminadas", a lo cual le sumamos el hecho de que lo hace entre tiburones. Sin 
embargo, no hay vuelta atrás, ya que como expone MONTORO CHINER: "El presente siglo será del Estado Ambiental de Derecho, o no será siglo".

\section{Bibliografía}

Benjamin, A. 2003, Obra colectiva "Direito Água e Vida", Volumen 1. O Estado teatral e a implementaçao do Direito Ambiental, de los trabajos presentados en el $7^{\circ}$ Congresso Internacional de Direito Ambiental, San Pablo 2 al 6 de junio de 2003.

Braga Navarro, G. 2015, Hermenéutica filosófica e direito ambiental: concretizando a justicia ambiental, Instituto O Direito por um Planeta Verde, São Paulo São Paulo, 2015.

Cafferatta, N. 2007, “De la efectividad del derecho ambiental”, La Ley, ejemplar del 2 de octubre.

Capella, V. 1994, Ecología: de las razones a los derechos. Granada, Ecorama.

González Ballar, R. 2007, Verdades incómodas sobre la gobernabilidad ambiental en Costa Rica, Editorial Jurídica Continental, San José.

Jordano Fraga, J. 2013, “El futuro del derecho ambiental”, Medio Ambiente \& Derecho, Revista Electrónica de Derecho Ambiental, Universidad de Sevilla, número 24.

Jordano Fraga, J. 2002, "Derecho Ambiental Siglo XXI", Medio y Derecho, Revista Electrónica de Derecho Ambiental, número 9, Universidad de Sevilla.

Morato Leito, J. R. y Ayala Araujo, P. 2010, Dano ambiental: do individual ao colectivo extrapatrimonial. 3 Edición. Sao Paulo.

Peña Chacón, M. 2014, "Hacia una nueva hermenéutica ambiental", Revista Justicia Ambiental, número 6, Chile.

Peña Chacón, M. 2014, “Aplicación de la regla de la norma más favorable en el derecho ambiental", Revista Iberoamericana de Derecho Ambiental y Recursos Naturales, número 11, Argentina.

Peña Chacón, M. 2013, “Test de Regresividad Ambiental”, Revista Internacional Direito Ambiental (RIDA), número 6, Brasil.

Prieur, M. 2012, El nuevo principio de no regresión en derecho ambiental, Bruxelles: Editions Bruylant.

Prieur, M. 1987, "La déréglementation en matière d'environnement", Revue juridique de l'environnement, número 3.

Ojeda Mestre, R. 2003, "El Derecho Ambiental del Siglo XXI", Medio Ambiente \& Derecho, Revista Electrónica de Derecho Ambiental, Universidad de Sevilla, número 9.

Ojeda Mestre, R. 2003, "Las cien caras del derecho ambiental”, Medio Ambiente \& Derecho, Revista Electrónica de Derecho Ambiental, Universidad de Sevilla, número 9. 
"LA REVISTA INNOVARE NO SE HACE RESPONSABLE EN NINGÚN CASO DE LOS CONTENIDOS, DATOS, CONCLUSIONES U OPINIONES VERTIDAS EN LOS ARTÍCULOS PUBLICADOS, SIENDO ESTA RESPONSABILIDAD EXCLUSIVA DEL (DE LOS) AUTOR (AUTORES)" 